\title{
Musculoskeletal Infections in Human Immunodeficiency Virus*
}

\author{
Honoré Ntsiba $^{1 \#}$, Madeleine Ngandeu-Singwé ${ }^{2}$ Akoli-Ekoya Ondzala ${ }^{1}$ \\ ${ }^{1}$ Rheumatology Department of Brazzaville University Teaching Hospital, Brazzaville, Congo; ${ }^{2}$ Yaoundé Central Hospital, Yaoundé, \\ Cameroun. \\ Email: "hntsiba@yahoo.fr
}

Received January $4^{\text {th }}, 2012$; revised February $7^{\text {th }}$, 2012; accepted February $15^{\text {th }}, 2012$

\begin{abstract}
Objective: To describe clinical, paraclinical and evolution's spectrum of musculoskeletal infections in patients with human immunodeficiency virus. Methods: Descriptive and analytical cross-study carried out on the file of 23.5\% presented a musculoskeletal infection among 85 who were infected with human immunodeficiency virus and hospitalized in the Rheumatology Department of Brazzaville Teaching Hospital during 3 years. Results: 7 males and 13 females all HIV/AIDS infected, average age of 35.2 years, range 18 and 68 years. Patients were at C and B stages of CDC Atlanta 1993 classification. We found 7 Pott's diseases, 7 septic arthritis and 6 pyomyositis. Pott's disease affected the lumbar spine in 4 cases, dorsolumbar curve 2 times, dorsal spine once and was complicated by paraplegia in 4 cases. Septic arthritis was exclusively localized at the knee, and myositis was located in the thigh in 3 cases, arm in 2 cases, and buttock in 2 cases, with multifocal localization in 2 cases. The most frequently isolated germ was Staphylococcus aureus; this was isolated 5 times at the knee and thrice in the muscle. The evolution was favorable under antibiotic therapy with recovery periods longer than that in the HIV negative patients. Conclusion: Musculoskeletal infections of HIV related patients have a profile which appears comparable to the immunocompetent patients. Pott's disease affected dorsal and lumbar spine, complicated by paraplegia. Septic arthritis is located on the knee and pyomyositis are frequent with unusual and multifocal localizations. The bacterial ecology is dominated by Staphylococcus aureus and Mycobacterium tuberculosis. The recovery is longer in these patients.
\end{abstract}

Keywords: Infection; Musculoskeletal; HIV/AIDS

\section{Introduction}

In Sub-saharan Africa, infections are a serious public health problem as a result of their high frequency and complications. When they affect the skeleton, they are usually diagnosed at a late stage, leading to important and irreversible articular and discovertebral damages that are responsible for definitive functional handicap [1-3]. These infections affect both immunocompetent subjects and HIV infected patients. In Congo Brazzaville where the prevalence of HIV is estimated at $3.2 \%$ in the general population [4], HIV infection will probably increase the incidence of osteoarticular infections and can modify the course of disease evolution. Living in an endemic zone of HIV, we wanted to know the clinical, paraclinical and evolution's profile of musculoskeletal infections occurring in HIV infected patients.

*Discloses: conflicts of interest: Honoré Ntsiba: none; Madeleine Ngandeu-Singwé: none; Akoli-Ekoya Ondzala: none.

\#Corresponding author.

\section{Methodology}

A cross-study review of all the files of patients with musculoskeletal infections followed up in the rheumatology unit of the University Teaching Hospital in Congo Brazzaville was conducted from January 2004 to December 2006. During this period, 544 patients where recruited, among whom 268 men (49\%) and 276 women (51\%).

Musculoskeletal infections were diagnosed base on clinical criteria including the presence of an infection syndrome with fever, existence of a local inflammation; biological criteria including the isolation of a microbial agent from joints fluid aspiration or specimen collection from an abscess or from a focal point and ESR greater than $50 \mathrm{~mm}$ in the first hour, level of C-reactive protein (CRP) greater than $6 \mathrm{mg} / \mathrm{l}$, leucocytosis greater than 10,000 white blood cells $/ \mathrm{mm}^{3}$. Radiological criteria for the diagnosis of septic arthritis or spondylodiscitis included the presence of epiphyseal demineralization and destruction, narrowing of joint or disc space and adjacent 
end plates (mirror erosion); for myosistis, the existence of abscess in soft tissue on ultrasound.

Systematic HIV testing of all patients with musculoskeletal infections was done. None of the patients were on antiretroviral treatment.

The remaining HIV negative patients, HIV+ patients with non-septic arthritis or inflammatory myositis were not included in this study. Percentage and statistic analysis were done by Epi-info.

\section{Results}

Guided by the above criteria we were led to retain 127 cases of musculoskeletal infections, giving hospital base infection prevalence in our department of $23 \%$. We found 85 HIV infected patients (15.6\%), 37 men (44\%) and 48 women (56\%). According to the CDC Atlanta 1993 classification, 8 (9\%) were at A stage, 52 at B stage (61\%) and 25 at C stage (30\%).

20/85 patients HIV+ (23.5\%) had musculoskeletal infections. Table 1 shows the distribution of musculoskeletal infections according to serostatus (HIV- or HIV+).

The study consisted of 7 male and 13 female patients, with age average of 35.2 years (range: 18 and 68 years). Infections included 7 cases of tuberculous spondylitis, 7 cases of septic arthritis and 6 cases of pyomyositis.

Pott's disease was observed in 2 men and 5 women with mean age of 36 years (range: 27 - 50 years). Tuberculous contact was found in 4 cases and a primary tuberculous infection in 6 cases. Clinically, gibbus deformity was found in 3 cases and paraplegia in 4 patients. Corticotherapy was not done to patients with paraplegia. The localization was lumbar in 4 cases, involving the dorsolumbar curve in 2 cases and the dorsal vertebrae in one case. The erythrocyte sedimentation rate (ESR) was increased in all patients, greater than $100 \mathrm{~mm}$ in the first hour. Radiographic signs were striking with demineralization of the vertebral end plates, disc space narrowing, mirror erosions, with important corporal damages (Figure 1). The ultrasound of the psoas muscle revealed an abscess in one case. Vertebral biopsy was not systematically. The average duration of hospitalization was 30 days. The recovery was based on complete disappearance of the infectious syndrome, local and biological signs of inflammation, stabilization and radiological consolidation in all the patients after anti-tuberculous treatment during 12 months with Ethambutol + Isoniazide + Rifampicine + Pyrazinamide (2 months), and Ethambutol + Isoniazide (10 months).

7 cases of septic arthritis were found in 5 women and 2 men with mean age of 42.8 years. The average duration before the first consultation was 7 days. A focal infection point was found in 4 patients. It was cutaneous and gynecological in 2 cases respectively. All cases of septic arthritis were monoarticular and affected exclusively the knee joints. In five cases, Staphylococcus aureus was the incriminated microorganism. A double antibiotic therapy with aminoglycosides and betalactamines $\mathrm{M}$ or quinolones led to remission in all cases in an average of 4 months, with mechanical sequelae in one case.

6 patients ( 3 men and 3 women) with mean age of 26.5 years, out of the fourteen cases of pyomyositis were HIV positive patients. A focal infection point was found in 4 patients, it was cutaneous and gynecological in 2 cases respectively. Myositis were all suppurative, located in the dorsal muscle in 2 cases, the thigh in 2 cases, the buttocks in 1 case, the arm in 1 case (Figure 2) and the supraspinatus muscle in one case, with multiple localization in 2 cases. S. aureus was isolated in 3 cases and

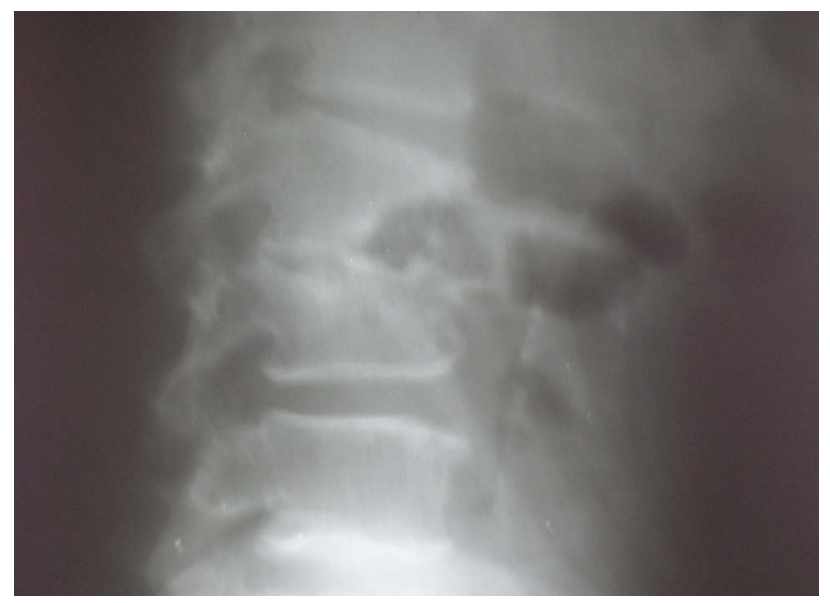

Figure 1. Pott's disease of lumbar spine (L2 - L3).

Table 1. Distribution of musculoskeletal infections according to immune status.

\begin{tabular}{lcccc}
\hline \multicolumn{1}{c}{ Infections } & $\begin{array}{c}\text { Patients HIV- } \\
\text { N (\%) }\end{array}$ & $\begin{array}{c}\text { Patients HIV+ } \\
\text { N (\%) }\end{array}$ & $\begin{array}{c}\text { Total } \\
\text { N (\%) }\end{array}$ & P value \\
\hline Tuberculous spondylodiscitis & $70(90)$ & $7(10)$ & $\mathbf{7 7}(60.5)$ & $\boldsymbol{P}<\mathbf{0 . 0 0 0 1}$ \\
Septic arthritis & $14(66)$ & $7(33)$ & $\mathbf{2 1}(16.5)$ & $\boldsymbol{P}=\mathbf{0 . 3}$ \\
Non specific bacterial spondylodiscitis & $13(100)$ & - & $\mathbf{1 3}(10.5 \%)$ & $\mathbf{1 0}$ \\
Pyomyositis & $8(57)$ & $6(43)$ & $\mathbf{1 4}(11 \%)$ & $\mathbf{0 . 9}$ \\
Osteitis & $2(100)$ & - & $\mathbf{2 ( 1 . 5 \% )}$ & $\mathbf{1 2 7 ( 1 0 0 )}$ \\
\multicolumn{1}{c}{ Total } & $\mathbf{1 0 7}(84)$ & $\mathbf{2 0}(16)$ & & \\
\hline
\end{tabular}




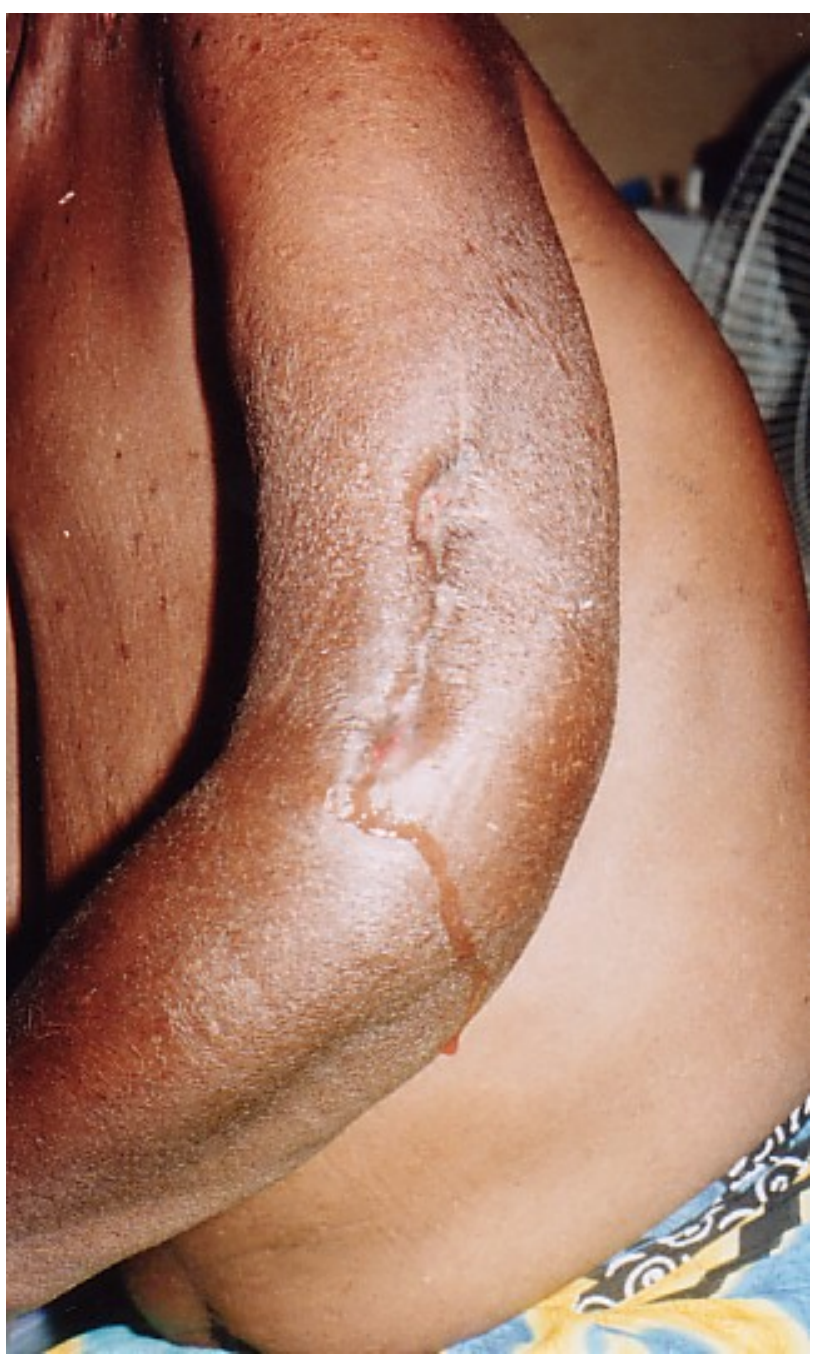

Figure 2. Left arm pyomyositis.

streptococcus once. Antibiotic treatment with Oxacillin or Erythromycin + Quinolone was instituted in all patients with surgical drainage in 2 cases. Recovery was obtained after institution of antibiotics therapy of up to 3 - 4 weeks duration.

No case of non specific bacterial spondylodiscitis or osteomyelitis was found among all HIV infected patients.

\section{Discussion}

Musculoskeletal manifestations in HIV infected patients vary, and sometimes constitute the initial mode of presentation of a retroviral infection. Bones, as well as joints or striated muscle [5-8] can be affected. Infections may affect peripheral joints, spine, long bones or muscles. The hospital frequency of musculoskeletal infections observed in our department (23\%), and the incidence of musculoskeletal infections in HIV+ patients (23.5\%) are higher than that described by other authors, with variation from 0.3 to $3.5 \%$ [9-15], probably by recruitment bias. In our department, 77 cases (60\%) of tuberculous spondylitis were reported, among them only 7 were HIV+ $(p<0.001)$; meanwhile, $7 / 14$ septic arthritis $(p=$ $0.3)$ and $6 / 8$ pyomyositis $(p=0.9)$ were observed in HIV related patients. This can suggest that in sub-Saharan Africa, Pott's disease is more frequent in HIV negative patients, but septic arthritis and pyomyositis are also frequent in HIV negative and HIV positive patients. So, Belzenugui found 21 cases of musculoskeletal infections amongst 1832 HIV positive patients, with frequency of $1.15 \%$ [9] and Weinstein described 13 vertebral infections amongst $7338 \mathrm{HIV}$, with a prevalence of $0.23 \%$ [11]. But in Rwanda where the seroprevalence of HIV/ AIDS is estimated at $30 \%$ in a study [16], $79 \%$ of septic arthritis was found in HIV positive patients. These results lead us to the hypothesis that, the number of septic arthritis could be correlated with the prevalence of retroviral infection.

The role of retroviral infections seems weak, and may not modify susceptibility to vertebral tuberculosis. While according to authors, HIV/AIDS is involved in 6\% to $17 \%$ of spondylitis infection [9,11,13]; in our study, 7/20 patients had Pott's disease. In a Spanish series of 556 immunodepressed patients monitored during 5 years, a single case of vertebral tuberculosis was found [9]. In Ivory Coast 28 cases of Pott's disease were described in immunocompetent patients [1], but in Burkina Faso, 32\% of patients suffering from Pott's disease had HIV/AIDS [2]. This can be explained by bias of recruitment.

Vertebral tuberculosis is most often of sub acute evolution; late diagnosis with neurological complications is common in more than half of the cases. The value and importance of the inflammatory syndrome, especially the ESR are partially explained by retroviral infection, and not only by bones, joints or muscles infections. In HIV positive patients the prolonged duration of treatment neither ameliorates therapeutic success rate nor the rate of recurrence [10-12,15].

The incidence of septic arthritis varies from 2 to 10 per 100,000 inhabitants in the general population in series of HIV related patients [10,12-15]. The knees are the most affected joints, also in HIV negative and HIV positive patients, mainly by S. aureus, witch is the most common microorganism found in septic arthritis irrespective of the patient's immune status $[9,10,12-16]$. These observations were similar to what we found in our series.

Pyomyositis is a primary infection of striated muscles common in African environment and as such it's also called tropical pyomyositis. It's responsible for $2 \%$ to $4 \%$ of admissions reported by several authors [9,17-19]. Many publications link retroviral infection to pyomyositis and some authors think that 1 in 2 cases of pyomyositis is a synonym of HIV infection [13,20,21]. Some African studies carried out in AIDS endemic zones confirmed 
this hypothesis [22,23]. In our study, 6/8 cases of pyomyositis were HIV+. Sporadic cases of pyomyositis are more and more described in temperate zones in HIV positive patients $[18,22]$. In immune competent subjects, pyomyositis is usually localized in the large muscle groups like the quadriceps, gluteus, and calf muscles, meanwhile, in HIV positive patients the pyomyositis sites are unusual and involve especially the dorsolumbar muscles, psoas muscles, and muscles of the hands and shoulder girdles; with multiple localizations which are explained by HIV infection $[14,15,18]$. We also observed this aspect in our study. S. aureus is the most frequent microorganism in pyomyositis, followed by streptococcus and Escherichia coli $[9,10,15,18]$. Treatment is longer in the HIV+ patients because by multiple localizations and large foci with extensive tissue necrosis $[12,15,18]$.

Musculoskeletal manifestations of HIV infected patients seem to be correlated with CD4 count [9-12,19,24]. In our study until 2006, CD4 count was not available, but patients were in B and C stage of CDC Atlanta 1993 classification.

In most series, HIV infection does not seem to favor non specific bacterial spondylodiscitis like in our study, but osteomyelitis is frequently described [10,14,15,19, 24]. Adult osteitis is rare in its hematogenous form. It most often results from infections awakening with reheating within a variable duration, or evolution of infantile osteomyelitis occurring mostly in sickle cell patients [3].

\section{Conclusion}

Musculoskeletal infections affect the immunocompetent as well as the HIV/AIDS patients. Pott's disease is found in both populations, more in HIV negative patients $(p<$ 0.0001 ), located on dorsal and lumbar spine and complicated by paraplegia. Septic arthritis is frequent (7/21), localized more often in the knee. Pyomyositis are also frequent in HIV+ patients (6/14) with multiple and unusual localizations. The bacterial ecology is the same, dominated by Staphylococcus aureus and Mycobacterium tuberculosis. Profile of septic arthritis and spondylitis are identical, but muscles infections seem frequent, evolution and recovery period are longer in cases of HIV positive patients, according to the CD4 cell count or the stage of HIV infection.

\section{Consent Section}

Written informed consent was obtained from the patients for publication of these cases and accompanying images.

This manuscript is currently neither under submission elsewhere nor has already been published elsewhere.

\section{Acknowledgements}

Dr. Kameni Dieudonné Ndjile, Rheumatologist, Laquinti- nie Hospital of Douala, Cameroun, for English translation revision.

\section{REFERENCES}

[1] D. N’Drioka, M. A. N’Dri-Yoboué, A. Varlet, A. Haidara and V. Bazeze, "Spine Tuberculosis. Epidemiologic and Diagnostic Aspects. A Study of 28 Clinical Observations,” Santé, Vol. 14, No. 2, 2004, pp. 81-84.

[2] J. Yilboudo, S. C. Da, S. I. Nacoulmas and E. Bandre, "Tuberculosis Spondylodiscitis with Neurological Troubles. Results of Surgical Treatment,” Medicine Tropicale, Vol. 62, No. 1, 2002, pp. 39-46.

[3] A. Moyikoua, B. Péna-Pitra, J. M. Ondzotto and J. M. Kaya, “Adults Ostomyelitis. 25 Cases Report,” Médecine D’Afrique Noire, Vol. 39, No. 11, 1992, pp. 749-751.

[4] Conseil National de Lutte Contre le SIDA, "Enquête de Séroprévalence et sur les Indicateurs du SIDA au Congo, (ESISC-1),” 2009, 173 p.

[5] A. A. Biviji, G. D. Paiement and L. S. Steinbach, "Musculoskeletal Manifestations of Human Immunodeficiency Virus Infection," The Journal of the American Academy of Orthopaedic Surgeons, Vol. 10, No. 5, 2002, pp. 312320.

[6] J. Tehranzadeh, R. R. Ter-Organesyan and L. S. Steinbach, "Musculoskeletal Disorders Associated with HIV Infection and AIDS. Part I: Infectious Musculoskeletal Conditions,” Skeletal Radiology, Vol. 33, No. 5, 2004, pp. 249-259. doi:10.1007/s00256-004-0764-z

[7] J. D. Reveille and F. M. Williams, "Infection and Musculoskeletal Conditions: Rheumatologic Complications of HIV Infection,” Best Practice and Research Clinical Rheumatology, Vol. 20, No. 6, 2006, pp. 1159-1179. doi:10.1016/j.berh.2006.08.015

[8] W. Louthrenoo, "Rheumatic Manifestations of Human Immunodeficiency Virus Infection," Current Opinion in Rheumatology, Vol. 20, No. 1, 2008, pp. 92-99. doi:10.1097/BOR.0b013e3282f1fea7

[9] J. Belzenugui, C. Gonzalez, L. Lopez, I. Plazaola, O. Maiz and M. Fignerroa, "Osteoarticular and Muscle Infectious Lesions in Patients with the Human Immunodeficiency Virus," Clinical Rheumatology, Vol. 16, No. 5, 1997, pp. 450-453. doi:10.1007/BF02238936

[10] D. Vasilopoulos, P. Chalasani, R. L. Jurado, K. Workowski and C. A. Agudelo, "Musculoskeletal Infections in Patients with Human Immunodeficiency Virus Infection," Medicine, Vol. 76, No. 4, 1997, pp. 284-294. doi:10.1097/00005792-199707000-00006

[11] M. A. Weinstein and F. Eismont, "Infections of the Spine in Patients with Human Immunodeficiency Virus," The Journal of Bone \& Joint Surgery, Vol. 87, No. 3, 2005, pp. 604-609. doi:10.2106/JBJS.C.01062

[12] J. Bahebeck, R. Bedimo, V. Eyenga, C. Kouamfack, T. Kingue, M. Nierenet, et al., "The Management of Musculoskeletal Infection in HIV Carriers,” Acta Orthopaedica Belgica, Vol. 70, No. 4, 2004, pp. 355-360.

[13] C. G. Zalavras, R. Dellamaggiora, M. J. Patzakis, E. Bav and P. D. Holtom, "Septic Arthritis in Patients with Im- 
munodeficiency Virus,” Clinical Orthopaedics and Related Research, Vol. 451, 2006, pp. 46-49. doi:10.1097/01.blo.0000229305.97888.17

[14] L. S. Steinbach, J. Tehranzadeh, J. L. Fleckenstein, W. J. Vanarthos and M. J. Pais, "Human Immunodeficiency Virus Infection: Musculoskeletal Manifestations," Radiology, Vol. 186, No. 3, 1993, pp. 833-838.

[15] R. A. Hughes, I. F. Rowe, D. Shanson and A. C. Keat, "Septic Bone, Joint and Muscle Lesions Associated with Human Immunodeficiency Virus Infection,” British Journal of Rheumatology, Vol. 31, No. 6, 1992, pp. 381-388. doi:10.1093/rheumatology/31.6.381

[16] A. Saraux, H. Taelman, P. Blanche, et al., "HIV Infection as a Risk Factor for Septic Arthritis," British Journal of Rheumatology, Vol. 36, No. 3, 1997, pp. 333-337. doi:10.1093/rheumatology/36.3.333

[17] I. Parasca, L. Damian and A. Albu, "Infectious Muscle Disease,” Romanian Journal of Internal Medicine, Vol. 44, No. 2, 2006, pp. 131-141.

[18] L. Lorente Otones, S. Vazquez Roman, G. Inigo Martin, P. R. Conejo and M. I. Gonzalez Tome, "Pyomyositis in Children: Not Only a Tropical Disease,” Annals de Pediatrla, Vol. 67, No. 6, 2007, pp. 578-581.
[19] M. S. Bicland, H. J. Longhurst and M. Murphy, "Osteomyelitis Complicating Pyomyositis in HIV Disease,” International Journal of STD and AIDS, Vol. 15, No. 9, 2004, pp. 632-634. doi:10.1258/0956462041724226

[20] D. Sissolak and W. R. C. Weir, "Tropical Pyomyositis,” Journal of Infection, Vol. 29, No. 2, 1994, pp. 121-127. doi:10.1016/S0163-4453(94)90530-4

[21] T. Balachandran and K. A. Mclean, "Pyomyositis Associated with AIDS,” AIDS, Vol. 4, No. 5, 1990, p. 471. doi:10.1097/00002030-199005000-00018

[22] C. Belec and D. Costanzob, "Pyomyositis and HIV Infection. 4 afrIcan Cases and Literature Review," Médecine et Maladies Infectieuses, Vol. 22, No. 8-9, 1992, pp. 712717. doi:10.1016/S0399-077X(05)81325-3

[23] W. B. Rodgers, M. Yodlowki and C. M. Mintzer, "Pyomyositis in Patient Who Have the Human Immunodeficiency Virus," Journal of Bone and Joint Surgery, Vol. 74, No. 4, 1993, pp. 588-592.

[24] E. Casado, A. Olive, S. Holgado, R. Perez-Andres, J. Romeu, J. C. Lorenzo, et al., "Musculoskeletal Manifestations in Patients Positive for Human Immunodeficiency Virus: Correlation with CD4 Count,” The Journal of Rheumatology, Vol. 28, No. 4, 2001, pp. 802-804. 